\title{
An Empirical Investigation of the Determinants of User Acceptance of Internet Banking
}

\author{
Patrick Y. K. Chau \\ School of Business \\ Faculty of Business and Economics \\ University of Hong Kong \\ Vincent S. K. Lai \\ Department of Decision Sciences and Managerial Economics \\ Faculty of Business Administration \\ Chinese University of Hong Kong
}

\begin{abstract}
The growth in the use of the Internet as a distribution channel of products and services offered by various businesses has been phenomenal. One such application is Internet banking services. As more and more financial institutions are finding ways to utilize Internet technologies to launch Internet banking services, an important issue is to understand what factors will impact the decisions of customers in adopting the service. Based on Davis's technology acceptance model with 4 additional variables that are theoretically justified as having influence on perceived usefulness and perceived ease of use, a research model for the investigated technology acceptance was developed and empirically examined, using responses from more than 160 intended users of the technology. Results of the data analysis generally support the model as well as 7 of 8 of the proposed hypotheses. In particular, personalization, alliance services, task familiarity, and accessibility were found to have significant influence on perceived usefulness and perceived ease of use, which, in turn, were found to be important factors in fostering a positive attitude toward accepting the services. Several implications for both research and practice have emerged and are discussed.
\end{abstract}

Internet banking services, technology acceptance, personalization, alliance services, task familiarity, accessibility

The authors thank Leung Bun and Wong Kam Man for their efforts in assisting the research and the data collection and the anonymous reviewers for valuable comments and suggestions on an earlier version of the article.

Correspondence and requests for reprints should be sent to Patrick Y. K. Chau, School of Business, Faculty of Business and Economics, University of Hong Kong, Pokfulam, Hong Kong. E-mail: Pchau@ business.hku.hk 


\section{INTRODUCTION}

The increasing popularity of the Internet has created great challenges for companies in various business sectors to promote and sell their products and services using this new distribution channel. One very responsive business sector to this change is the banking sector. To sustain business competitiveness, more and more banks or financial services companies are transforming from their traditional approach of "bricks and mortar" into a "clicks and mortar" one under the recent emergence of electronic commerce and business. As noted by Beikier et al. [1], "physical banks are not an anachronism, but less is sometimes more."

For achieving different competitive strategies, which include cost containment, performance improvement, market penetration, and product transformation, banks and financial services companies are finding ways to utilize Internet technologies and to launch Internet banking services [2]. These companies are also keen to understand how their customers value their Internet banking services to help the banks devise strategic plans and capture market share. In other words, an important question for a successful launch of an Internet banking service is to ask what factors will impact the decisions of customers in adopting the service. In information systems (IS) research terms, it is the issue of user technology acceptance.

The primary objective of this study is to investigate the user technology acceptance issue in the context of Internet banking. Based on an extended technology acceptance model (TAM), this research aims to make a contribution to information technology (IT) acceptance/adoption research by advancing the understanding of user technology acceptance and extending the theoretical validity and empirical applicability of the existing literature to Internet banking, an area that has become increasingly important in the world of electronic commerce. Furthermore, identifying the critical factors that have significant impact on the acceptance of Internet banking can meet a pragmatic need for managers in the banking sector to devise effective strategies for developing Internet banking as a new distribution channel for banking services.

The rest of the article is organized as follows. In the next section, we present the background of this study and its research motivations. The research model, together with the research hypotheses, is then described, followed by a description of the study design and data collection procedures details. The discussion section presents the important results of the study. The article concludes with a summary of the study's findings, a review of its limitations, and analysis of its implications for both IS researchers and Internet banking managers in financial institutions.

\section{BACKGROUND AND RESEARCH MOTIVATIONS}

User technology acceptance has received wide and intense interest among IS researchers (e.g., [3-10]). The factors that are significant in technology acceptance have been examined across varied information technologies and user populations [11]. It is fair to say that a cumulative tradition has already been established in user 
technology acceptance research, especially in the management and IS disciplines. Of all the models proposed, the TAM proposed by Davis [12] has been widely referenced and adopted by IS researchers. In short, TAM posits that two variables, namely perceived usefulness and perceived ease of use, are the primary constructs determining attitudes toward adopting IT, the intention to use the technology, and the actual usage. These two constructs have generally been confirmed in many empirical studies to be important factors in affecting system usage [3, 4, 13, 14]. Their explanatory power and the generalizability of TAM have also been examined and supported in many studies [3, 4, 7, 8, 15-17].

However, since the "original" development of TAM was established with studies of fairly simple or unsophisticated IT tools (such as word processing, spreadsheet, and e-mail) in a typical business environment, the theoretical validity and empirical applicability of the model needs to be extended to incorporate different technologies, users, and organizational contexts [11]. Many researchers have attempted to do so and have expanded or modified the original model to make it more complete theoretically. Taylor and Todd [18], for example, extended TAM by integrating it with the theory of planned behavior to explain and predict the use of a computer resources center. Chau [4, 19] extended and modified TAM, respectively, in two different technology acceptance studies to evaluate the acceptance of different ITs by different user groups in different organizational contexts. More recently, Venkatesh $[9,10,17]$ investigated the role of intrinsic motivation and emotion in user technology acceptance.

In studying the acceptance of Internet banking, we argue that the original TAM is insufficient because the technology setting of and the transaction environment in Internet banking are drastically different when compared with conventional IT and the typical business environment. Instead of adopting a software package/tool (e.g., a word processing or e-mail software package) and a development methodology (e.g., CASE or object-oriented programming), the context in Internet banking is to adopt a new task/technology environment. Prior to acceptance, users of Internet banking services need to grasp the contribution that adopting the technology environment will make to rendering their banking activities easier. In this regard, we suggest the addition of a number of "external" variables to the model to provide a more comprehensive theoretical perspective of user technology acceptance in the context of Internet banking.

\section{RESEARCH MODEL AND HYPOTHESES}

Our research model is depicted in Figure 1. As shown, the proposed model extends TAM and includes several external variables that are argued to have influence on either perceived usefulness or perceived ease of use in the context of adopting Internet banking services.

Instead of using intention to adopt the Internet banking services or actual usage of the services as the dependent variable of the research model, attitude toward adopting the services is used for both theoretical and practical reasons. Theoretically speaking, it has been demonstrated that only when intention to use is well formed does it completely capture the effect of attitude on actual usage [20]. 


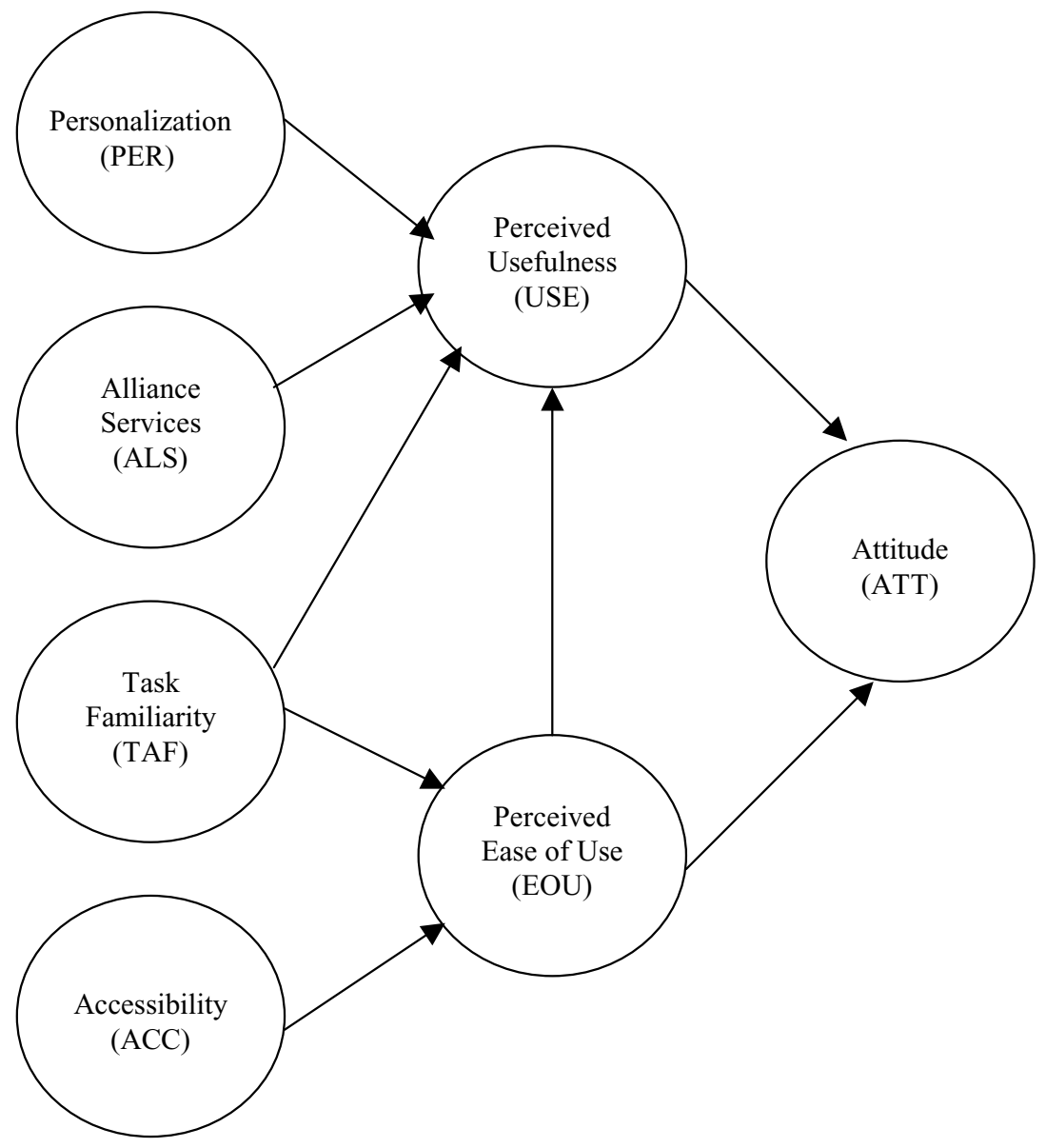

Figure 1. Research Model.

In other words, in cases when intention is poorly formed, attitude will thus have a direct effect on usage. Moreover, Bagozzi [21] found a similar direct effect between attitude and usage when behavior requires low to moderate effort to use the technology. This "attitude predicting usage" relationship is empirically supported by both Al-Gahtani and King [22] and Winter et al. [23]. In our study context, Internet banking is certainly not an established service provided to bank customers or the service itself would require a lot of effort to (learn to) use the technology. Therefore, it is theoretically justifiable that the intention construct be dropped in preference for measuring whether attitude has a direct effect on usage.

Second, since Internet banking was still in its infancy stage in Hong Kong (where the research was conducted) at the time of conducting this research, both the number of banks offering Internet banking services and the number of clients who had adopted the services were still limited. Hence, this practical reason or limitation has caused us to focus on the attitude construct. We contend that 
attitude would predict the actual usage when the supply of Internet banking services becomes more common, as argued earlier.

\subsection{Factors Affecting Perceived Usefulness}

Three factors, personalization, alliance services, and task familiarity, are proposed to have influence on perceived usefulness.

With the interactive feature of browsers and their global reach, the Internet is considered an appropriate platform on which to implement one-to-one marketing and customer relationship management [24, 25]. Dysart [26] argued that the most successful Internet platform will be one that can offer each visitor a highly personalized interactive experience. The Web site should be designed around an action-driven interactive paradigm, in which every element of the site blends together to enable a visitor to accomplish a task quickly. This means that individual customer information can be collected and the product/service mix can be customized for individual customer needs. Simply put, the Internet marketplace supports personalization in two ways. First, consumer-tracking technology allows the identification of individual buyers. Second, information-rich products lend themselves to cost-effective personalization [27].

Specifically in the context of Internet banking, Rubin [28] pointed out that new Web-based technologies are enabling banks to provide customized content that can educate and cross-sell while strengthening the long-term relationship between banks and customers. Such personalization can offer much convenience to customers and it is generally believed to have direct association with users' perceptions of the usefulness of the services. For customers, Internet banking represents anytime, anywhere banking. For bankers, dynamic personalization and customization represents anytime, anywhere relationship building [28]. The customer need not tell the bank his or her needs and preferences every time when doing banking tasks. After-sales services would also be facilitated through personalization. Hence, personalization is postulated to have a positive effect on perceived usefulness as stated in the following hypothesis:

H1: Personalization is positively related to perceived usefulness.

The Internet is also believed to be a ubiquitous and low-cost platform for implementing interorganizational systems [29]. Through alliances with other organizations, a range of new services transcending organizational boundaries can be offered to users. Given customer needs and the interorganizational integration attribute of the Internet, the sources of differentiation for banking services become multiple. Moreover, allied financial service products can include cheaper niche products, cross-border selling, selling knowledge, payments, customer relationships, and new markets [2]. It may also reflect the advantage of the Internet as an interorganizational system platform that can offer added values to customers. With these alliance services, customers can complete a whole task in one stop, in contrast with visiting multiple organizations in the past. Therefore, it is contended that alliance services have a positive impact on perceived usefulness. We therefore posit: 
H2: Alliance services are positively related to perceived usefulness.

In the context of IT adoption, task familiarity represents the degree of nonvariability and certainty of activities that a user needs to resolve when using the technology. Internet banking has been viewed as a delivery channel that is compatible with conventional banking systems, whereby users perform common banking transactions in a manner compatible to brick-and-mortar practices [30,31]. When there is a good match of tasks performed through Internet banking and through the existing system, users will spend less time translating task activities between the two systems, thereby enhancing the perceived usefulness of Internet banking. In other words, the more familiar is the task to be performed, the greater is the likelihood that a user will use the system, since little or no extra cognitive learning efforts will be required. This self-efficacy trait, which is reflective of the confidence in one's ability to perform a particular task, has accumulated empirical support as an important antecedent of perceived usefulness [32]. Based on this reasoning, it is postulated that:

H3: Task familiarity is positively related to perceived usefulness.

\subsection{Factors Affecting Perceived Ease of Use}

The research model proposes two variables that have influence on perceived ease of use. They are task familiarity and accessibility.

As stated earlier, task familiarity represents the degree of nonvariability and certainty of activities that a user needs to resolve when using the technology. When nonvariability and certainty in the task domain are high, the work performed tends to be more structured and predictable, and the information processing requirements tend to be minimal [33]. In contrast, as task variability and uncertainty increase, the problem becomes more unstructured, and the assessment of events and the specification of appropriate rules and procedures become difficult, thus leading to a perception of "difficult-to-perform-the-task."

In the context of Internet banking, although it was developed with the intention of providing customers with effortless point-and-click operations, some users might still be frustrated by the unfamiliarity of performing the task in the new Internet environment. Following the foregoing task familiarity argument, we contend that whether or not a user perceives the task (in our case, using the Internet banking services) to be familiar may have a significant influence on perceived ease of use. Therefore, it is postulated that:

H4: Task familiarity is positively related to perceived ease of use.

Another factor that may have influence on perceived ease of use is accessibility, as suggested and empirically supported by Karahanna and Straub [34]. In their study, accessibility is a multidimensional construct encompassing both physical terminal access and system usage ability. They argue that the more accessible an information system is, the less effort is needed to use it. In the context of Internet 
banking, accessibility refers to not only the physical accessibility of Internet connections, but also the global and round-the-clock nature of Internet banking. Goh [35] argued that if the supporting technological infrastructures are easily and readily available, Internet commerce applications such as Internet banking will become more feasible. Tan and Teo [36] concurred with this argument and postulated that accessibility of Internet banking is a facilitator of adoption due to its capacity of allowing users to perceive the technology more favorably. Based on the foregoing, we propose the following hypothesis:

H5: Accessibility is positively related to perceived ease of use.

Echoing other TAM research studies, this study postulates that perceived ease of use influences both perceived usefulness and attitude, whereas perceived usefulness is also a determinant of attitude. In our context, we argue that the degree to which the Internet banking service is perceived to be easy to use by its intended user affects his or her perception of the technology's usefulness and the attitude to adopt this technology. Following the same reasoning, the level of usefulness of Internet banking, as perceived by the users, also influences their attitude toward adopting the technology. The three corresponding hypotheses are as follows:

H6: Perceived ease of use is positively related to perceived usefulness.

H7: Perceived ease of use is positively related to attitude toward the adoption.

H8: Perceived usefulness is positively related to attitude toward the adoption.

\section{RESEARCH METHODOLOGY}

\subsection{Instrument Development and Pretest}

A questionnaire was developed to be the instrument for data collection. Question items used, in most cases, were adapted from prior literature using a 7-point Likert scale with anchors ranging from strongly agree to strongly disagree.

When developing the questionnaire, content validity was established through careful selection and adaptation of items from previously validated instruments. After that, the questionnaire was pretested by two business professors with expertise in survey research and 11 bank customers with Internet banking experience. The feedback from the pilot test was used to improve the readability and the quality of the questions in the instrument.

Personalization measures were derived from Rubin's [28] study of Internet banking customization. Based on Rubin's elaboration, personalization was designed to measure the perceived extent of Internet banking on customized presentation, customized content, personal message delivery, tracking individual access patterns, as well as tailor-made offerings on products/services.

Alliance services mean the level of cross-organizational services offered to customers via alliances among services rendered by various organizations with the 
bank's Web site acting as the single point of access. Its measures were derived from Vitale and Johnson's [37] study of alliance services associated with interorganizational systems. In light of his alliance discussion, measurements were developed to operationalize different facets of Internet banking collaboration services on integration of services across organizational boundary, provision of one-stop services, and expanded and differentiated services enabled by a bank's system integration with third parties over the Internet.

Task familiarity has been studied extensively and many validated instruments have also been developed (e.g., $[33,38,39]$ ) and used in a diverse range of disciplines, including IS and management. This study synthesized these studies and identified three widely used items, which were then adapted as our measures for task familiarity. These items include routine ways, understandable procedures, and established practices for performing banking tasks.

Accessibility was measured by a scale adapted from Culnan [40] in assessing user perceptions of information accessibility when using computer-based IS. Two items were used to reflect the global and round-the-clock nature of Internet banking.

Studies on perceived usefulness, perceived ease of use, and attitude toward the adoption have been well researched, especially in the context of TAM applications. Measures for these constructs have also been developed, validated, and adopted in many technology adoption studies. In this study, the items used to measure perceived usefulness, perceived ease of use and attitude toward the adoption were adapted from Davis [6] and Teo et al. [41]. The Appendix, Table A.1, lists the items used in the study with references for their sources.

\subsection{Participants}

The participants used in the study were business executives who were pursing advanced business degrees at a major university in Hong Kong on a part-time basis. They were considered appropriate as a result of a series of consultations with several experienced bankers who were in charge of the Internet banking services of their respective financial institutions. These banking professionals unanimously indicated that the targeted user group for their Internet banking services would be college-educated, computer-literate 25 - to 45 -year-olds. The questionnaires were distributed during class. Individuals were informed that participation in the study was voluntary and that the participant's individual responses would be treated with strict confidence.

\section{DATA ANALYSIS AND RESULTS}

\subsection{Sample Characteristics}

Four hundred and twenty-four questionnaires were distributed and 174 were returned. Seven of them were partially completed and therefore excluded from the data analysis, resulting in a total of 167 effective responses (40\%). Of the 167 
usable questionnaires, the majority of the respondents (134 respondents, 79\%) fell into the age group of 25 to 45 years, which matches the target user group of the Internet banking services. They practiced a variety of occupations including accountancy, banking, marketing, business consultancy, IT positions, engineering, social work, and medicine. The distribution of gender was quite balanced, with 68 of the participants $(41 \%)$ being women.

Although only 13 of the respondents (8\%) had actually used Internet banking services, the majority of them (120 respondents, $72 \%$ ) had experience in using other remote banking services such as telephone banking. All of them also had experience in using the Internet.

\subsection{Analysis of Measurement Model}

The measurement model for the seven constructs was assessed by a confirmatory factor analysis using LISREL 8.30. Six common model fit measures were used to assess the measurement model's overall goodness-of-fit: chi-square/degree of freedom, goodness-of-fit index (GFI), adjusted goodness-of-fit index (AGFI), nonnormed fit index (NNFI), comparative fit index (CFI), and standardized root mean square residual (SRMSR). The chi-square statistic was not included because of its inherent problem with sample size [42]. The observed values were 1.75, $0.85,0.79,0.92,0.94$, and 0.05 for the six indexes, respectively. Except for the GFI and AGFI values, all others surpassed the recommended minimum threshold [43], suggesting an adequate, though not very good, model fit.

The measurement model was further assessed for construct reliability and validity. Construct reliability was assessed at two levels: item reliability and composite reliability. Item reliability indicates the amount of variance in an item due to the underlying construct rather than to error and can be obtained by squaring the factor loading. An item reliability of at least .50 is considered to be evidence of reliability. Composite reliability can be calculated as follows: (square of the summation of the factor loadings)/[(square of the summation of the factor loadings) + (summation of error variances)]. The interpretation of the resultant coefficient is similar to that of Cronbach's alpha, except that it takes into account the actual factor loadings rather than assuming that each item is equally weighted in the composite load determination. As shown in Table 1, all item reliabilities surpassed the required minimum, except one for task familiarity, which was .48 and slightly below the required minimum. Also, with the exception of accessibility, the composite reliability for all the constructs was above .80 . The composite reliability for accessibility was .69 , which is close to .70, an acceptable threshold suggested by Nunnally and Bernstein [44].

Construct validity was evaluated by convergent and discriminant validity. Convergent validity can be assessed by factor loading and the average variance extracted. A factor loading greater than .70 is considered significant and as evidence of convergent validity. The average variance extracted measures the amount of variance that is captured by the construct in relation to the amount of variance due to measurement error and can be calculated using the following formula: (summation of the squared factor loadings)/[(summation of the squared 
Table 1

Summary of Measurement Scales

\begin{tabular}{|c|c|c|c|c|c|c|}
\hline Construct & $M$ & $S D$ & $\begin{array}{c}\text { Factor } \\
\text { Loading }\end{array}$ & $\begin{array}{c}\text { Item } \\
\text { Reliability }\end{array}$ & $\begin{array}{l}\text { Composite } \\
\text { Reliability }\end{array}$ & $\begin{array}{l}\text { Average } \\
\text { Variance } \\
\text { Extracted }\end{array}$ \\
\hline \multicolumn{7}{|c|}{ Personalization } \\
\hline PER1 & 5.51 & 1.23 & .78 & .61 & \multirow{4}{*}{.89} & \multirow{4}{*}{.67} \\
\hline PER2 & 5.49 & 1.20 & .83 & .69 & & \\
\hline PER3 & 5.28 & 1.33 & .84 & .71 & & \\
\hline PER4 & 5.26 & 1.30 & .82 & .67 & & \\
\hline \multicolumn{7}{|c|}{ Alliance services } \\
\hline ALS1 & 4.87 & 1.32 & .84 & .71 & \multirow{3}{*}{.89} & \multirow{3}{*}{.74} \\
\hline ALS2 & 4.92 & 1.36 & .88 & .77 & & \\
\hline ALS3 & 5.07 & 1.24 & .85 & .72 & & \\
\hline \multicolumn{7}{|c|}{ Task familiarity } \\
\hline TAF1 & 2.69 & 1.26 & .76 & .58 & \multirow{3}{*}{.81} & \multirow{3}{*}{.59} \\
\hline TAF2 & 2.63 & 1.11 & .85 & .72 & & \\
\hline TAF3 & 2.58 & 1.20 & .69 & .48 & & \\
\hline \multicolumn{7}{|c|}{ Accessibility } \\
\hline ACC1 & 4.64 & 1.94 & .72 & .52 & \multirow[t]{2}{*}{.69} & \multirow[t]{2}{*}{.53} \\
\hline ACC2 & 5.13 & 1.66 & .73 & .53 & & \\
\hline \multicolumn{7}{|c|}{ Perceived usefulness } \\
\hline USE1 & 4.73 & 1.39 & .80 & .64 & \multirow{4}{*}{.91} & \multirow{4}{*}{.72} \\
\hline USE2 & 4.77 & 1.40 & .83 & .69 & & \\
\hline USE3 & 4.84 & 1.34 & .92 & .85 & & \\
\hline USE4 & 4.83 & 1.32 & .86 & .74 & & \\
\hline \multicolumn{7}{|c|}{ Perceived ease of use } \\
\hline EOU1 & 5.44 & 1.32 & .76 & .58 & \multirow{3}{*}{.83} & \multirow{3}{*}{.66} \\
\hline EOU2 & 4.80 & 1.42 & .79 & .62 & & \\
\hline EOU3 & 5.08 & 1.29 & .88 & .77 & & \\
\hline \multicolumn{7}{|l|}{ Attitude } \\
\hline ATT1 & 4.86 & 1.37 & .91 & .83 & \multirow{3}{*}{.94} & \multirow{3}{*}{.85} \\
\hline ATT2 & 4.86 & 1.34 & .94 & .88 & & \\
\hline ATT3 & 4.94 & 1.40 & .91 & .83 & & \\
\hline
\end{tabular}

Note. $\mathrm{PER}=$ personalization; $\mathrm{ALS}=$ alliance services; $\mathrm{TAF}=$ task familiarity; $\mathrm{ACC}=$ accessibility; $\mathrm{USE}=$ perceived usefulness $; \mathrm{EOU}=$ perceived ease of use; $\mathrm{ATT}=$ attitude.

factor loadings) + (summation of the error variances)]. If the average variance extracted is less than .50, the variance due to measurement error is greater than the variance due to the construct itself. In this case, the convergent validity of the construct is questionable. Also shown in Table 1, except one item for task familiarity, all factor loadings of the items in the measurement model exceeded .70 and all average variances extracted were greater than .50, thereby demonstrating adequate convergent validity.

Discriminant validity can be assessed by comparing the shared variances among constructs with the average variance extracted on the individual constructs. Lower shared variances among constructs than the average variance extracted on the individual constructs suggest discriminant validity. Table 2 presents the shared variances among constructs. The results provide positive support for the discriminant validity. 
Table 2

Variance Extracted

\begin{tabular}{|c|c|c|c|c|c|c|c|}
\hline Construct & PER & $A L S$ & $T A F$ & $A C C$ & USE & EOU & ATT \\
\hline PER & .67 & & & & & & \\
\hline ALS & .03 & .74 & & & & & \\
\hline TA & .17 & .06 & .59 & & & & \\
\hline ACC & .21 & .06 & .06 & .53 & & & \\
\hline USE & .20 & .05 & .00 & .26 & .72 & & \\
\hline EOU & .16 & .13 & .06 & .23 & .49 & .66 & \\
\hline ATT & .11 & .11 & .00 & .15 & .45 & .42 & .85 \\
\hline
\end{tabular}

Note. Diagonals represent the average variance extracted. Other entries represent the shared variance. $\mathrm{PER}=$ personalization; $\mathrm{ALS}=$ alliance services; $\mathrm{TAF}=$ task familiarity; $\mathrm{ACC}=$ accessibility; USE $=$ perceived usefulness; EOU = perceived ease of use; $\mathrm{ATT}=$ attitude.

\subsection{Model Testing Results}

The research model was tested against the data collected using LISREL 8.30. Using the sample covariance matrix (Appendix, Table A.2), we examined the structural model in terms of model goodness-of-fit, overall explanatory power, and postulated individual causal links.

As in the case for the measurement model, the overall goodness-of-fit was examined using the following six common model fit measures: chi-square/degree of freedom, GFI, AGFI, NNFI, CFI, and SRMSR. As summarized in Figure 2, the research model exhibited a satisfactory, though not very good, fit with the data collected from the respondents.

The explanatory power of the research model was examined in terms of the portion of variance explained. The analysis results suggested that the model was capable of explaining 55\% of the variance in users' attitudes toward adopting the Internet banking services. Furthermore, $69 \%$ of the observed variance in perceived usefulness appeared to have been explained jointly by perceived ease of use, personalization, task familiarity, and alliance services, whereas $29 \%$ of the variance in perceived ease of use was accounted for by accessibility.

The significance and the relative strength of individual links specified by the research model were also evaluated. Also shown in Figure 2, seven of the eight postulated paths were found to be statistically significant: one at the .01 level, and six at the .001 level. Specifically, the paths from perceived usefulness and perceived ease of use to attitude were both significant. Accessibility, but not task familiarity, significantly influenced perceived ease of use. Perceived usefulness was significantly influenced by perceived ease of use, personalization, task familiarity, and alliance services, as hypothesized. Therefore, except for Hypothesis 4, all the hypotheses were supported.

The strength of each individual path was assessed in terms of the standardized path coefficient, ranging from -1 to +1 . Table 3 summarizes both direct and indirect effects of the respective factors. Compared with other factors, perceived ease of use exhibited the strongest direct, indirect, and total effects on users' attitudes 


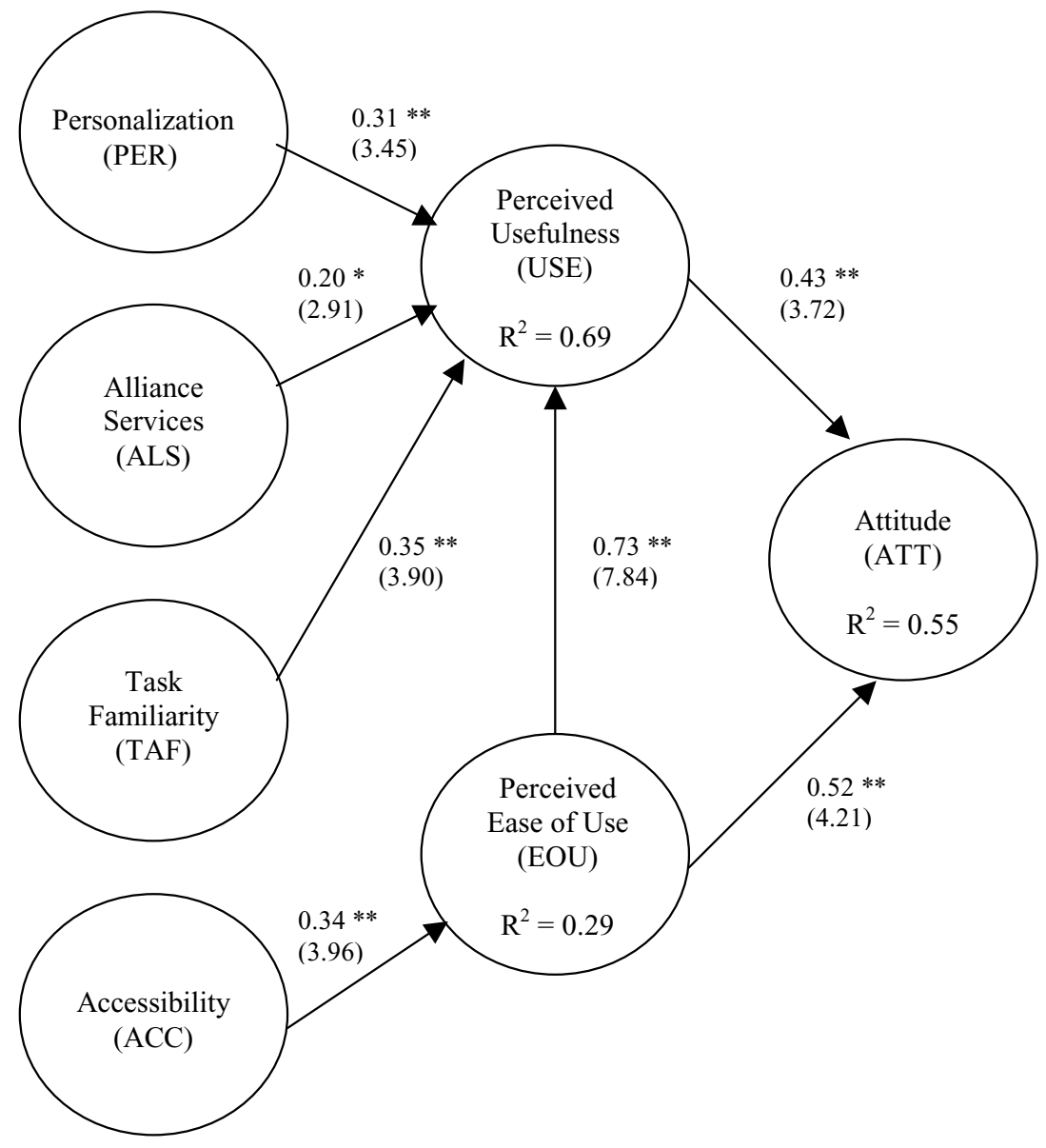

$\begin{array}{llll}\text { Path coefficient } & \text { Chi-square / d.o.f. } & = & 1.89 \\ (\mathrm{t}-\text { value }) & \text { GFI } & = & 0.83 \\ & \text { AGFI } & = & 0.78 \\ * \quad \text { p-value }<0.01 & \text { NNFI } & = & 0.91 \\ * * \quad \text { p-value }<0.001 & \text { CFI } & = & 0.92 \\ & \text { SRMSR } & = & 0.09\end{array}$

Figure 2. Results of the model test (only significant paths are shown). GFI = goodness-of-fit index; AGFI = adjusted goodness-of-fit index; NNFI = nonnorm fit index; CFI = comparative fit index; SRMSR = standardized root mean square residual.

toward accepting Internet banking services. Perceived usefulness was the second strongest and accessibility was the third through its influence on both perceived usefulness and perceived ease of use. Though with weaker effects than the preceding three factors, task familiarity, personalization, and alliance services also exhibited positive influences on attitude through significant influence on perceived usefulness. 
Table 3

Strengths of Individual Factors

\begin{tabular}{lc}
\hline Effect on Attitude & Effect Size \\
\hline Direct effect & \\
USE & .43 \\
EOU & .52 \\
Indirect effect & \\
EOU & .31 \\
PER & .13 \\
ALS & .09 \\
TAF & .15 \\
ACC & .28 \\
Total effect & \\
USE & .43 \\
EOU & .83 \\
PER & .13 \\
ALS & .09 \\
TAF & .15 \\
ACC & .28 \\
\hline
\end{tabular}

Note. USE = perceived usefulness; EOU = perceived ease of use; $\mathrm{PER}=$ personalization; $\mathrm{ALS}=$ alliance services; $\mathrm{TAF}=$ task familiarity; $\mathrm{ACC}=$ accessibility.

\section{DISCUSSION}

This study examined Internet banking acceptance by potential users. Based on Davis's technology acceptance model with four additional variables that were theoretically justified to have influence on perceived usefulness and perceived ease of use, a research model for the investigated technology acceptance was developed and empirically examined, using responses from more than 160 intended users of the technology. Results obtained from the structural equation modeling analysis indicate that the research model exhibited a satisfactory overall fit to the collected data and was capable of providing a reasonable explanation of user's acceptance of Internet banking services. Seven of eight causal links specified by the model were supported at different statistical significance levels and exhibited relative strength at various levels. A detailed discussion of each individual path follows.

\subsection{Significance of Perceived Ease of Use and Perceived Usefulness}

Results of the study showed that perceived ease of use might be the single most significant determinant of users' acceptance of Internet banking. This observed significant effect of perceived ease of use on Internet banking acceptance may reflect the concern of the newness of the Internet environment to users. This also indicates or confirms the importance of the role of perceived ease of use in the early adoption stage of a new technology [45]. In this light, to be accepted by the users, any Internet banking services should be designed with a very good Web interface in terms of its ease of use. 
In addition to its strong direct effect on attitude, perceived ease of use exhibited a considerable indirect effect on attitude, via perceived usefulness, which, by itself, also had a significant influence on attitude. These two findings suggest the importance of having the services being perceived useful by the users. Financial institutions that consider (or are) offering Internet banking services may need to consider formulating strategies that can lead to developing positive perceptions of the usefulness of the services, particularly in situations where perceived ease of use alone cannot bring about a desired level of positive attitudes toward adopting the technology.

The strong direct and indirect effects of perceived ease of use on attitude can be explained as follows. The easier Internet banking is to use, the greater will be a user's feelings of self-competence and determination. Such feelings may increase a user's intrinsic motivation, which in turn will lead to the exploration of detailed system functions and features, thereby increasing perceived system usefulness [41]. Consequently, favorable users' attitudes on Internet banking will be created, which will eventually motivate them to spend more time navigating the cyberworld of banking while conducting their banking activities. In this regard, a bank should be concerned not only with designing a user-friendly interface, but also providing expanded banking services to enhance system usage.

\subsection{Significance of Proposed External Variables}

Personalization was found to be a significant factor on perceived usefulness. There are at least two plausible explanations. First, as argued earlier, the Internet banking environment is a new environment that advocates one-to-one and relationship marketing. Many banks even provide their customers with more personalized services by allowing them to access not only their accounts and historical transactions, but also other related applications and data that may be of interest to them. Thus, users would probably expect value-added services to be obtained from using the system. In other words, the more personalization features that a user anticipates the Internet banking environment will provide, the higher the degree of usefulness he or she may perceive from using the services. Second, as more and more Internet banking services are launched, users might expect the sophistication of content, service, and functionality to continue to improve. Banks, therefore, have to segment their Web-site investments into public site functionality and private site capabilities to provide more personalized information and advice for different groups of customers. Beyond fundamental transactional functionality, Internet banking might include financial planning services and site customization that will provide more valuable and targeted data for their users, prompting them to visit more frequently to consolidate the usefulness of the system.

Alliance services show a significant effect on perceived usefulness. This observed importance of alliance services appears to suggest that customers are not expecting to use the Internet banking services only for single or simple tasks/transactions. Instead, they expect that they can get multiple services or "one-stop comprehensive financial services" as promoted by some financial institutions. Those banks that provide Internet banking services, therefore, need to continue to innovate by building links to other institutions' services and other new services that will impress users with the usefulness of adopting Internet 
banking services. They might also consider strategically partnering with major third-party vendors to boost the customer base as well as revenue streams and think of themselves as intermediaries that will provide end-to-end delivery and fulfillment of banking and other financial-related services to their customers.

Task familiarity appears to have significant influence on perceived usefulness but not perceived ease of use. These findings are somewhat expected and unexpected. The expected part is that task familiarity has been validated to be a determinant of usefulness. In diffusion of innovation terms, usefulness can be mapped to the concept of "relative advantage," which is the degree to which the innovation is perceived to be better than existing practices [46]. Judging from both efficiency and effectiveness perspectives, Internet banking has outperformed over-the-counter banking services [30], thereby justifying its relative advantage or usefulness. As Keil et al. [47] argued, usefulness is seen as a function of task/tool fit. If Internet banking is judged to be more useful, whereas task familiarity remains high, then switching to online banking would seem to be a better task/tool fit. Furthermore, performing similar tasks on the Internet does not necessitate a steep learning curve or invoke any complexity that would outweigh the potential benefits of using Internet banking, thus explaining the significant impact of task familiarity on usefulness.

Somewhat unexpected in this study is the insignificance of task familiarity on ease of use. A plausible explanation for the finding of insignificance may be that the simple tasks that in most cases a user would perform in an Internet banking environment, for example, checking balances, or transferring money from one account to another, are already familiar to the user. In terms of the operating procedures, performing such tasks in the Internet banking environment or via an autoteller machine would be quite similar. Therefore, whether or not the task is familiar is not an important issue, because users are already quite familiar with the procedures. Nevertheless, as argued earlier, the significances of personalization and of alliance services on the acceptance decision might make this task familiarity become an important issue as the services develop.

Accessibility was found to be a significant factor on perceived ease of use. This finding is expected given that the first step in using Internet banking services is to get connected or access to the Web site successfully. If a user finds it difficult to gain access to the services, he or she might be very frustrated and would therefore form a negative perception on the ease of use of the services. Therefore, this observed strong influence may motivate bankers to redesign their Internet banking promotion strategies by making effective use of wireless technology. With the influx of third-generation wireless technology, which offers a transmission speed of up to 2 megabits per $\mathrm{s}$ in an "always-connected" mode, the accessibility to Internet banking will be significantly improved, which in turn will offer more opportunities for users to learn to use different features of the system.

\section{LIMITATIONS}

This study has several limitations. Although the research results suggest several significant factors affecting the acceptance of Internet banking, the discussed findings and implications nevertheless are based on a single study that involved a 
specific user group in a particular geography. Therefore, caution needs to be taken when extrapolating or generalizing these research results to other user groups in other geographies and business/social environments. Although using students at tertiary education institutions as subjects in academic research is quite common, researchers still challenge whether students differ systematically from the target population in general about their perceptions of the technology of the phenomenon of interest. This may indeed be critical in cases where students have not clarified their attitudes or where social norms play a critical role in the theoretical model of interest [32]. In this study, though student participants were used to examine the Internet banking phenomenon, they were all full-time employees with several years of working experience. More importantly, they fit the profile of the desired potential users of Internet banking and had well-formed perceptions and attitudes toward this information technology.

Second, the choice of attitude as the dependent variable, though with both theoretical and practical justification, still limits the explanatory power of the model. On the research side, the model is not complete as compared with models investigated in other technology acceptance studies. On the practice side, Internet banking services providers would be interested in not just their potential customers' attitudes toward adopting their services, but also their intention to use and their expected usage.

Third, personalization is a complicated construct, and depending on its definition, it may have different effects in different contexts. This complication could introduce cross or interaction effects among the investigated constructs. In our study, we adopted the definition by Rubin [28] in which personalization is more associated with the task itself, and items that are used to operationalize the construct are mainly related to satisfying the needs for performing the task. This is why we only hypothesized the relationship between personalization and usefulness but not between personalization and ease of use.

Finally, although the research model explained over half of the variance of the dependent variable $\left(R^{2}=.55\right)$, which is comparable to results in most prior TAM studies (e.g., $[7,18]$ ), the unexplained $45 \%$ of variance suggests that there is an omission of factors important to acceptance of Internet banking services by users. Perhaps this is also an issue TAM researchers need to contemplate. Many empirical studies of TAM have examined simple end-user technologies. One may wonder whether the constructs and models of TAM are equally applicable to more complex technologies such as Internet banking. Perhaps a richer set of variables needs to be examined as predictors of TAM to provide better explanatory power for the model.

\section{CONCLUSIONS}

As more and more financial institutions launch their Internet banking services, examinations of factors critical to technology acceptance by intended users become increasingly important. Of particular interest and importance to IS research is whether there are some additional factors that are significant in the adoption decision and that might differ from those reported by prior IT acceptance/adoption 
studies. Drawn from a well-researched and proven theoretical model, a research model for Internet banking acceptance was proposed and empirically tested against data collected from more than 160 potential users of Internet banking services. Results of the data analysis generally support the model and seven of eight proposed hypotheses. In particular, personalization, alliance services, task familiarity, and accessibility were found to have significant influence on perceived usefulness or perceived ease of use, which, in turn, were found to be important factors in fostering positive attitudes toward accepting the services. Several implications for both research and practice emerged and are now discussed.

\subsection{Implications for Research}

Results of the study support the addition of the four proposed external variables in explaining the effect of perceived usefulness and perceived ease of use on attitude. In particular, the findings of the significant influences of personalization, alliance services, and task familiarity on perceived usefulness and of accessibility on perceived ease of use are important and worth future study. Whereas task familiarity may be considered an old variable (as it has been investigated in many prior technology adoption studies), the other three, that is, personalization, alliance services, and accessibility, are new to technology adoption research in general and TAM studies in particular. Given the growing number of electronic commerce applications, including Internet banking services, the positive and significant results obtained in this study suggest that more research effort be focused on these factors.

The finding of perceived ease of use as the most significant factor affecting the attitude toward adopting the technology prompts us to retest or reconfirm the significance of this factor in the adoption cycle. Whereas many recent IT adoption studies have shown the diminishing significance of perceived ease of use on adoption decisions when the technology concerned is commonly used in the user community (e.g., word processing packages and e-mail applications), it is worthwhile and important to examine the significance of perceived ease of use in the adoption cycle of Internet banking services. If the findings of prior IT adoption studies are correct, this factor would become less and less significant in terms of affecting the attitude toward adopting the technology when Internet banking becomes more and more popular and the Web interface becomes more and more user-friendly. A follow-up or longitudinal study, therefore, is suggested or even deemed necessary.

Looking at the research model as a whole shows that the extended TAM has a strong explanatory power with $55 \%$ of variance in attitude toward adopting Internet banking explained. As the Internet connects more and more people and organizations, more innovative, advanced, and complicated technologies are expected to be invented. Such a model framework might provide and promote a more comprehensive understanding of the acceptance of electronic commerce applications in general and Internet banking in particular.

In addition, this study brings an international perspective to IT acceptance/adoption research. Rosenzweig [48] challenged the presumption of conceptual equivalence across language and cultural barriers in management 
research. To be useful, research results must be validated in a larger context, providing additional empirical support for research findings that subsequently can be generalized or considered applicable in different cultural settings. In this connection, this study represents an effort toward validating previous research results in a different context by examining the acceptance of Internet banking services by users in Hong Kong. Conceivably, users from a different culture may exhibit interesting differences in technology assessment. Similarly, the exact technology acceptance decision factors essential to individual users and their precise effects might subtly vary in cultures characterized by considerable differences in levels of individualism. As the Internet is a global network encompassing different countries, organizations, and individuals, these factors might differ in different organizational environments, possibly resulting in different individual behaviors.

The discussed limitations and implications single out several important future research directions. First, continued effort is needed to validate and improve the research model, both its theoretical basis and its empirical applicability. For instance, identification of additional variables to explain the observed attitude variations not accounted for by the current research model is essential. Two plausible theoretical constructs might be trust and privacy, which have been suggested to be two very important factors in electronic commerce [49-52]. When properly included and combined with those already identified by the research model, these factors may provide a fuller explanation of the technology acceptance of interest.

Second, further investigative efforts are needed to reexamine the validity of our framework and to expand the generalizability of our findings. Longitudinal investigations involving different contexts defined by technology and user groups may be effective in addressing the needs for increased validity and generalizability. The anticipated research results conceivably may advance our understanding of the underlying causality between or among the important decision variables and, at the same time, validate comparative research findings on user technology acceptance in the context of an Internet environment.

Third, as discussed and explained in Section 3, neither behavioral intention nor actual usage was examined in our research model. A follow-up study is thus deemed worthwhile or even necessary wherein the two factors mentioned earlier, or at least one of them, can be included in the research model to make it not just a more complete TAM, but also one that gives results that can be compared with prior TAM studies.

\subsection{Implications for Internet Banking Management Practice}

From a managerial standpoint, the findings of this study reveal the importance of cultivating and solidifying a positive perception of how easy a technology is to use and how useful it is to the intended user group. In particular, compared with ease of use, the technology's usefulness might be important in technology acceptance but to a reduced extent. Therefore, managers who are (or consider) offering Internet banking services should consider placing a high priority on demonstrating the ease of use of the technology and communicating its services and valueadded features through a well-designed Web interface. 
The observed significance of personalization and alliance services also suggests interesting and important implications for Internet banking management practice. Bank customers are demanding in using Internet banking services. Although most Internet banking services provide customers with simple and unsophisticated services, customers do see the importance of the provision of personalization and multiple alliance services in making Internet banking useful. These results agree with most Internet banking strategies in which many simple transaction services are regarded as the first phase only. More important developments will provide integrated services such as one-stop comprehensive financial services, which can lead to a huge cost reduction in customer services. The finding of a significant influence of personalization and alliance services on perceived usefulness suggests their possible long-term decisive impact on Internet banking acceptance.

Accessibility is found to correlate significantly with ease of use and has an indirect impact on users' attitude. This suggests to managers that improvements in accessibility could possibly augment the ease of use of Internet banking, which, in turn, could improve users' attitudes and eventually a system's adoption. In viewing of the advantage of its broadband multimedia attribute, management might consider exploiting third-generation wireless technology to enhance Internet banking services. Another option is to reconfigure their automatic teller machine network to encompass Internet capability.

Finally, the observed significance of task familiarity on usefulness, but not on ease of use, conveys a message to managers for their policy formulations. Conceivably, there are already routine ways, understandable procedures, and established practices that are compatible with over-the-counter services for performing Internet banking services. Hence, the manager's role in task familiarity should be focused not on making Internet banking easier to use, but instead on making it more useful.

\section{REFERENCES}

[1] M. M. Beikier, D. K. Flur, and S. J. Saingham, "A future for bricks and mortar," McKinsey Quarterly, vol. 3, pp. 78-85, 2000.

[2] Mary J. Cronin (Ed.), Banking and Finance on the Internet. New York: Van Nostrand Reinhold, 1997.

[3] D. A. Adams, R. R. Nelson, and P. A. Todd, "Perceived usefulness, ease of use, and usage of information technology: A replication," MIS Quarterly, vol. 16, no. 2, pp. 227-247, 1992.

[4] P. Y. K. Chau, "An empirical assessment of a modified technology acceptance model," Journal of Management Information Systems, vol. 13, no. 2, pp. 185-204, 1996.

[5] W. W. Chin and P. A. Todd, "On the use, usefulness, and ease of use of structural equation modeling in MIS research: A note of caution," MIS Quarterly, vol. 19, no. 2, pp. 237-246, 1995.

[6] F. D. Davis, "Perceived usefulness, perceived ease of use, and user acceptance of information technology," MIS Quarterly, vol. 13, no. 3, pp. 319-339, 1989.

[7] K. Mathieson, "Predicting user intention: Comparing the technology acceptance model with theory of planned behavior," Information Systems Research, vol. 2, no. 3, pp. 173-191, 1991.

[8] D. Straub, M. Keil, and W. Brenner, "Testing the technology acceptance model across cultures: A three-country study," Information and Management, vol. 33, no. 1, pp. 1-11, 1997.

[9] V. Venkatesh, "Determinants of perceived ease of use: Integrating control, intrinsic motivation, and emotion into the technology acceptance model," Information Systems Research, vol. 11, no. 4, pp. 342-365, 2000. 


\section{CHAU AND LAI}

[10] V. Venkatesh and F. D. Davis, "A model of the perceived ease of use development and test," Decision Sciences, vol. 27, no. 3, pp. 451-481, 1996.

[11] P. J. H. Hu, P. Y. K. Chau, O. R. Sheng, and K. Y. Tam, "Examining technology acceptance model using physician acceptance of telemedicine technology," Journal of Management Information Systems, vol. 16, no. 2, pp. 91-112, 1999.

[12] F. D. Davis, A technology acceptance model for empirically testing new end-user information systems: Theory and results. Doctoral dissertation, Sloan School of Management, Massachusetts Institute of Technology, Cambridge, Massachusetts, 1986.

[13] A. R. Hendrickson and M. R. Collins, "An assessment of structure and causation of IS usage," Data Base, vol. 27, no. 3, pp. 61-67, 1996.

[14] G. H. Subramanian, "A replication of perceived usefulness and perceived ease of use measurement," Decision Sciences, vol. 25, nos. 5/6, pp. 863-874, 1994.

[15] D. Gefen and D. W. Straub, "Gender differences in the perception and use of e-mail: An extension to the technology acceptance model," MIS Quarterly, vol. 21, no. 4, pp. 389-400, 1997.

[16] B. Szajna, "Empirical evaluation of the revised technology acceptance model," Management Science, vol. 42, no. 1, pp. 85-92, 1996.

[17] V. Venkatesh and M. G. Morris, "Why don't men ever stop to ask for directions? Gender, social influence, and their role in technology acceptance and usage behavior," MIS Quarterly, vol. 24, no. 1, pp. 115-139, 2000.

[18] S. Taylor and P. A. Todd, "Understanding information technology usage: A test of competing models," Information Systems Research, vol. 6, no. 2, pp. 144-176, 1995.

[19] P. Y. K. Chau, "An empirical investigation on factors affecting the acceptance of CASE by system developers," Information and Management, vol. 30, no. 6, pp. 269-280, 1996.

[20] R. P. Bagozzi and Y. Yi, "The degree of intention formation as a moderator of the attitude-behavior relationship," Social Psychology Quarterly, vol. 52, pp. 266-279, 1989.

[21] R. P. Bagozzi, "The level of effort required for behaviors as a moderator of the attitude-behavior relation," European Journal of Social Psychology, vol. 20, pp. 266-279, 1990.

[22] S. S. Al-Gahtani and M. King, "Attitudes, satisfaction and usage: Factors contributing to each in the acceptance of information technology," Behaviour and Information Technology, vol. 18, no. 4, pp. 277-297, 1999.

[23] S. J. Winter, K. M. Chudoba, and B. A. Gutek, "Attitudes toward computers: When do they predict computer use," Information and Management, vol. 34, no. 5, pp. 275-284, 1998.

[24] J. Holland and S. M. Backer, "Customer participation in creating site brand loyalty." Journal of Interactive Marketing, vol. 15, no. 4, pp. 34-45, 2001.

[25] J. Wind and A. Rangaswamy, "Customerization: The next revolution in mass customization," Journal of Interactive Marketing, vol. 15, no. 1, pp. 13-32, 2001.

[26] J. Dysart, "eGenie site leads way in personalization," Advertising Age's Business Marketing, vol. 83, no. 10, p. 33, 1998.

[27] Y. Bakos, "The emergent role of electronic marketplaces on the Internet," Communications of the ACM, vol. 41, no. 8, pp. 35-41, 1998.

[28] I. Rubin, "Personalizing the Internet," Banking Strategies, vol. (Sept/Oct), pp. 6-10, 1998.

[29] L. M. Applegate, F. W. McFarlan, and J. L. McKenney, "Corporate Information Systems Management." Singapore: Irwin/McGraw-Hill, 1997.

[30] H. M. Deitel, P. J. Deitel, and K. Steinbuhler, E-Business \& E-Commerce for Managers. Englewood Cliffs, NJ: Prentice Hall, 2000.

[31] S. Liao, P. S. Yuan, H. Wang, and A. Chen, "The adoption of virtual banking: An empirical study," International Journal of Information Management, vol. 19, no. 1, pp. 63-74, 1999.

[32] R. Agarwal and E. Karahanna, "Time flies when you're having fun: Cognitive absorption and beliefs about information technology usage," MIS Quarterly, vol. 24, no. 4, pp. 665-694, 2000.

[33] K. K. Kim and N. S. Umanath, "Structure and perceived effectiveness of software development subunits: A task contingency analysis," Journal of Management Information Systems, vol. 9, no. 3, pp. 157-181, 1992-1993.

[34] E. Karahanna and D. W. Straub, "The psychological origins of perceived usefulness and ease-ofuse." Information and Management, vol. 35, pp. 237-250, 1999.

[35] H. P. Goh, The diffusion of Internet in Singapore. Academic exercise, Faculty of Business Administration, National University of Singapore, 1995. 
[36] M. Tan and T. S. H. Teo, "Factors influencing the adoption of Internet banking," Journal of the Association for Information Systems, vol. 1, no. 5, pp. 1-44, 2000.

[37] M. R. Vitale and H. R. Johnson, “Creating competitive advantage with interorganizational information systems," MIS Quarterly, vol. 22, no. 2, pp. 153-165, 1998.

[38] R. L. Daft, R. H. Lengel, and L. K. Trevino, "Message equivocality, media selection manager performance: Implications for information systems," MIS Quarterly, vol. 11, no. 3, pp. 355-366, 1987.

[39] V. Lai, "A contingency of CASE-task fit on software developer's performance." European Journal of Information Systems, vol. 8, no. 1, pp. 27-39, 1999.

[40] Mary J. Culnan, "The dimensions of perceived accessibility to information: Implications for the delivery of information systems and services," Journal of the American Society for Information Science, vol. 36, no. 5, pp. 302-308, 1985.

[41] T. S. H. Teo, V. K. G. Lim, and R. Y. C. Lai, "Intrinsic and extrinsic motivation in Internet usage," Omega: International Journal of Management Science, vol. 27, no. 1, pp. 25-37, 1999.

[42] J. Hartwick and H. Barki, "Explaining the role of user participation in information systems use," Management Science, vol. 40, no. 4, pp. 440-465, 1994.

[43] P. Y. K. Chau, "Reexamining a model for evaluating information center success using a structural equation modeling approach," Decision Sciences, vol. 28, no. 2, pp. 309-334, 1997.

[44] J. C. Nunnally and I. H. Bernstein, Psychometric Theory, 3rd ed. New York: McGraw-Hill, 1994.

[45] K. Mathieson and M. Keil, "Beyond the interface: Ease of use and task/technology fit," Information and Management, vol. 34, no. 4, pp. 221-230, 1998.

[46] E. M. Rogers, Diffusion of Innovations. Free Press: New York, 1983.

[47] M. Keil, P. M. Beranek, and B. R. Konsynski, “Usefulness and ease of use: Field study evidence regarding task consideration," Decision Support Systems, vol. 13, no. 1, pp. 75-91, 1995.

[48] P. M. Rosenzweig, "When can management science research be generalized internationally?," Management Science, vol. 40, no. 1, pp. 28-39, 1994.

[49] D. L. Hoffman, "Building consumer trust online," Communications of the ACM, vol. 42, no. 4, pp. $80-85,1999$.

[50] S. Jones, "Trust requirements in e-business," Communications of the ACM, vol. 43, no. 12, pp. 80-89, 2000.

[51] D. Schoder, "Building firm trust online," Communications of the ACM, vol. 43, no. 12, pp. 73-79, 2000.

[52] R. P. Srivastava and T. J. Mock, "Evidential reasoning for Webtrust assurance services," Journal of Management Information Systems, vol. 16, no. 3, pp. 11-32, 1999-2000. 
144 CHAU AND LAI

\section{APPENDIX}

Table A.1 lists the questions used in this study and Table A.2 gives the covariance matrix.

Table A.1

Question Items Used in the Study

\begin{tabular}{|c|c|c|}
\hline Construct & Measure & Source \\
\hline Personalization & & [28] \\
\hline PER1 & $\begin{array}{l}\text { Internet Banking enables me to customize the presentation of } \\
\text { information on a bank's Web site according to my } \\
\text { personal needs }\end{array}$ & \\
\hline PER2 & $\begin{array}{l}\text { Internet Banking enables me to customize the content of information } \\
\text { on a bank's Web site according to my personal needs }\end{array}$ & \\
\hline PER3 & $\begin{array}{l}\text { Internet Banking enables a bank to deliver personalized messages } \\
\text { to me (e.g., via e-mail) }\end{array}$ & \\
\hline PER4 & $\begin{array}{l}\text { Internet Banking enables a bank to personalize service/product } \\
\text { offerings to me after learning my banking behaviors and preferences }\end{array}$ & \\
\hline Alliance services & & [37] \\
\hline ALS1 & $\begin{array}{l}\text { By system integration with other parties via the Internet, banks } \\
\text { can provide me with integrated services, which are traditionally } \\
\text { offered by separate units/organizations }\end{array}$ & \\
\hline ALS2 & $\begin{array}{l}\text { By system integration with other parties via the Internet, banks } \\
\text { can provide one-stop services to me }\end{array}$ & \\
\hline ALS3 & $\begin{array}{l}\text { By system integration with other parties via the Internet, banks } \\
\text { can provide expanded services to me }\end{array}$ & \\
\hline Task familiarity & & {$[33,39]$} \\
\hline TAF1 & There is a clearly known way to do banking tasks I normally encounter & \\
\hline TAF2 & $\begin{array}{l}\text { There is an understandable sequence of steps that can be followed to } \\
\text { do banking tasks I normally encounter }\end{array}$ & \\
\hline TAF3 & $\begin{array}{l}\text { I can rely on established practices to do banking tasks I normally } \\
\text { encounter }\end{array}$ & \\
\hline Accessibility & & [40] \\
\hline ACC1 & I can use Internet banking at any time of a day & \\
\hline ACC2 & I can use Internet banking at anywhere in the world & \\
\hline $\begin{array}{l}\text { Perceived } \\
\text { usefulness }\end{array}$ & & {$[6,41]$} \\
\hline USE1 & I can accomplish my banking tasks more quickly using Internet banking & \\
\hline USE2 & I can accomplish my banking tasks more easily using Internet banking & \\
\hline USE3 & Internet Banking enhances my effectiveness in utilizing banking services & \\
\hline USE4 & Internet banking enhances my efficiency in utilizing banking services & \\
\hline $\begin{array}{l}\text { Perceived ease } \\
\text { of use }\end{array}$ & & {$[6,41]$} \\
\hline EOU1 & Learning to use internet banking is easy for me & \\
\hline EOU2 & I find it easy to use Internet banking to accomplish my banking tasks & \\
\hline EOU3 & Overall, I believe Internet banking is easy to use & \\
\hline Attitude & & {$[6,41]$} \\
\hline ATT1 & In my opinion, it is desirable to use Internet banking & \\
\hline ATT2 & I think it is good for me to use Internet banking & \\
\hline ATT3 & Overall, my attitude toward internet banking is favorable & \\
\hline
\end{tabular}

Note. $\mathrm{PER}=$ personalization; $\mathrm{ALS}=$ alliance services; $\mathrm{TAF}=$ task familiarity $; \mathrm{ACC}=$ accessibility; $\mathrm{USE}=$ perceived usefulness; $\mathrm{EOU}=$ perceived ease of use; $\mathrm{ATT}=$ attitude. 
Table A.2

Covariance Matrix

\begin{tabular}{lrrrrrrrrrrr}
\hline & TAF1 & TAF2 & TAF3 & ACC1 & ACC2 & PER1 & PER2 & PER3 & PER4 & ALS1 & ALS2 \\
\hline TAF1 & 1.58 & & & & & & & & & & \\
TAF2 & 0.90 & 1.23 & & & & & & & & & \\
TAF3 & 0.81 & 0.77 & 1.45 & & & & & & & & \\
ACC1 & -0.45 & -0.45 & -0.22 & 3.77 & & & & & & & \\
ACC2 & -0.46 & -0.41 & -0.32 & 1.70 & 2.77 & & & & & & \\
PER1 & -0.47 & -0.48 & -0.53 & 0.26 & 0.20 & 1.50 & & & & & \\
PER2 & -0.45 & -0.47 & -0.40 & 0.33 & 0.42 & 1.10 & 1.43 & & & & \\
PER3 & -0.46 & -0.52 & -0.45 & 0.33 & 0.18 & 0.94 & 1.08 & 1.78 & & & \\
PER4 & -0.49 & -0.40 & -0.35 & 0.25 & 0.29 & 0.96 & 0.99 & 1.37 & 1.70 & & \\
ALS1 & -0.24 & -0.29 & -0.29 & 0.40 & 0.37 & 0.61 & 0.57 & 0.60 & 0.41 & 1.74 & \\
ALS2 & -0.33 & -0.40 & -0.29 & 0.60 & 0.40 & 0.77 & 0.69 & 0.69 & 0.53 & 1.34 & 1.86 \\
ALS3 & -0.28 & -0.25 & -0.24 & 0.53 & 0.43 & 0.66 & 0.61 & 0.54 & 0.50 & 1.20 & 1.25 \\
EOU1 & -0.61 & -0.36 & -0.28 & 0.72 & 0.63 & 0.54 & 0.47 & 0.49 & 0.49 & 0.54 & 0.72 \\
EOU2 & -0.35 & -0.15 & -0.15 & 0.98 & 0.45 & 0.48 & 0.52 & 0.63 & 0.50 & 0.65 & 0.83 \\
EOU3 & -0.30 & -0.25 & -0.17 & 0.68 & 0.53 & 0.53 & 0.50 & 0.62 & 0.50 & 0.54 & 0.72 \\
USE1 & -0.14 & 0.06 & 0.01 & 0.60 & 0.07 & 0.50 & 0.48 & 0.52 & 0.55 & 0.63 & 0.72 \\
USE2 & -0.18 & 0.03 & 0.08 & 0.49 & 0.20 & 0.53 & 0.48 & 0.55 & 0.56 & 0.69 & 0.77 \\
USE3 & -0.24 & -0.10 & -0.02 & 0.75 & 0.26 & 0.66 & 0.51 & 0.66 & 0.67 & 0.64 & 0.89 \\
USE4 & -0.09 & -0.08 & -0.06 & 0.68 & 0.30 & 0.64 & 0.70 & 0.88 & 0.68 & 0.80 & 0.90 \\
ATT1 & -0.08 & 0.04 & -0.01 & 0.76 & 0.52 & 0.38 & 0.44 & 0.53 & 0.57 & 0.59 & 0.51 \\
ATT2 & -0.10 & -0.01 & 0.00 & 0.80 & 0.68 & 0.37 & 0.45 & 0.51 & 0.48 & 0.65 & 0.53 \\
ATT3 & -0.12 & -0.09 & -0.03 & 0.80 & 0.56 & 0.43 & 0.48 & 0.50 & 0.56 & 0.60 & 0.69 \\
\hline & ALS3 & EOU1 & EOU2 & EOU3 & USE1 & USE2 & USE3 & USE4 & ATT1 & ATT2 & ATT3 \\
\hline TAF1 & & & & & & & & & & & \\
& & & & & & & & & \\
\end{tabular}

TAF1

TAF2

TAF3

ACC1

ACC2

PER1

PER2

PER3

PER4

ALS1

ALS2

ALS3 1.54

EOU1 $0.66 \quad 1.75$

$\begin{array}{llll}\text { EOU2 } & 0.72 & 1.07 & 2.03\end{array}$

$\begin{array}{lllll}\text { EOU3 } & 0.64 & 1.21 & 1.24 & 1.67\end{array}$

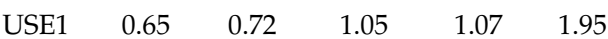

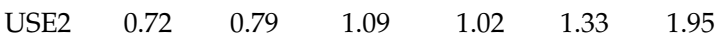

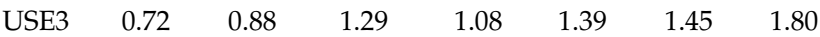

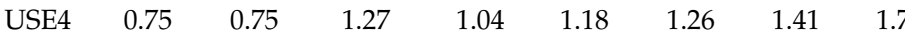

$\begin{array}{llllllllll}\text { ATT1 } & 0.60 & 0.87 & 0.97 & 1.04 & 1.11 & 0.98 & 1.06 & 1.05 & 1.88\end{array}$

$\begin{array}{lllllllllll}\text { ATT2 } & 0.60 & 0.90 & 1.04 & 1.08 & 0.97 & 0.97 & 0.99 & 0.98 & 1.59 & 1.81\end{array}$

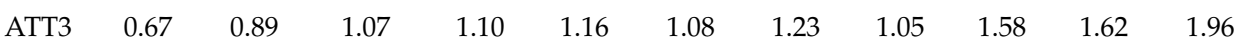

Note. $\mathrm{TAF}=$ task familiarity; $\mathrm{ACC}=$ accessibility; $\mathrm{PER}=$ personalization; $\mathrm{ALS}=$ alliance services; $\mathrm{EOU}=$ perceived ease of use; USE = perceived usefulness; ATT = attitude. 